\title{
Mineral-Ground Micro-Fibrillated Cellulose Reinforcement for Polymer Compounds
}
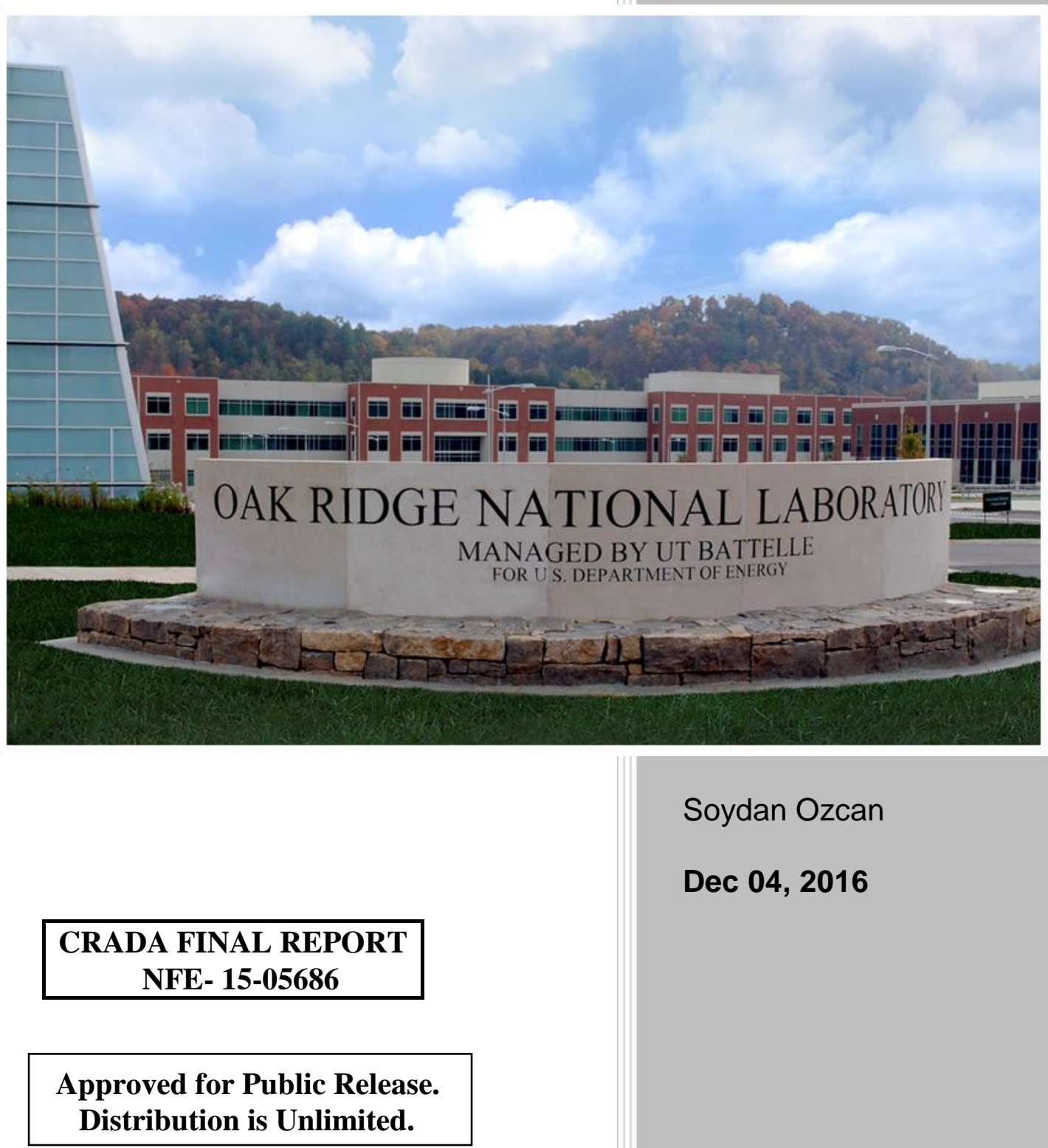

Soydan Ozcan

Dec 04, 2016 


\title{
DOCUMENT AVAILABILITY
}

Reports produced after January 1, 1996, are generally available free via US Department of Energy (DOE) SciTech Connect.

Website http://www.osti.gov/scitech/

Reports produced before January 1, 1996, may be purchased by members of the public from the following source:

\author{
National Technical Information Service \\ 5285 Port Royal Road \\ Springfield, VA 22161 \\ Telephone 703-605-6000 (1-800-553-6847) \\ TDD 703-487-4639 \\ Fax 703-605-6900 \\ E-mail info@ntis.gov \\ Website http://www.ntis.gov/help/ordermethods.aspx
}

Reports are available to DOE employees, DOE contractors, Energy Technology Data Exchange representatives, and International Nuclear Information System representatives from the following source:

Office of Scientific and Technical Information

PO Box 62

Oak Ridge, TN 37831

Telephone 865-576-8401

Fax 865-576-5728

E-mail reports@osti.gov

Website http://www.osti.gov/contact.html

This report was prepared as an account of work sponsored by an agency of the United States Government. Neither the United States Government nor any agency thereof, nor any of their employees, makes any warranty, express or implied, or assumes any legal liability or responsibility for the accuracy, completeness, or usefulness of any information, apparatus, product, or process disclosed, or represents that its use would not infringe privately owned rights. Reference herein to any specific commercial product, process, or service by trade name, trademark, manufacturer, or otherwise, does not necessarily constitute or imply its endorsement, recommendation, or favoring by the United States Government or any agency thereof. The views and opinions of authors expressed herein do not necessarily state or reflect those of the United States Government or any agency thereof. 
ORNL/TM-2016/716

CRADA/NFE-15-05686

Material Science and Technology Division Advanced Manufacturing Office

\title{
Mineral-Ground Micro-Fibrillated Cellulose Reinforcement for Polymer Compounds
}

\author{
Authors \\ Jon Phipps \\ Sean Ireland \\ David Skuse \\ Martha Edwards \\ Leslie McLain \\ Halil Tekinalp \\ Lonnie Love \\ Vlastimil Kunc \\ Soydan Ozcan
}

Date Published:

December 4, 2016

Prepared by

OAK RIDGE NATIONAL LABORATORY

Oak Ridge, Tennessee 37831-6283

managed by

UT-BATTELLE, LLC

for the

US DEPARTMENT OF ENERGY

under contract DE-AC05-00OR22725

Approved For Public Release 


\section{CONTENTS}

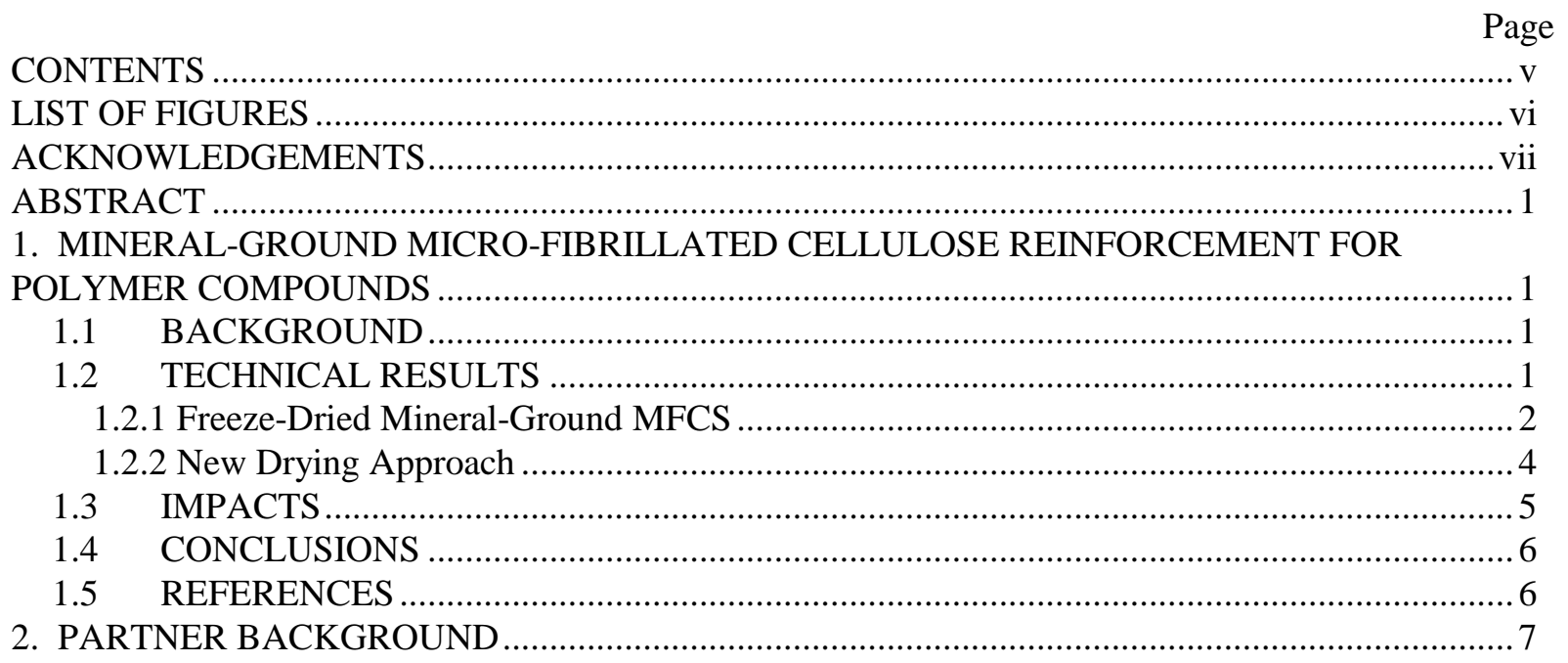




\section{LIST OF FIGURES}

Fig. 1. Tensile strength of composites prepared using freeze-dried Fiberlean..................................... 2

Fig. 2. Elastic modulus of composites prepared using freeze-dried Fiberlean....................................... 3

Fig. 3. Earbud case that was 3D-printed using 10\% freeze-dried fiberlean and PLA........................... 3

Fig. 4. Tensile strength of composites prepared using Fiberlean dried with new approach. ................. 4

Fig. 5. Elastic modulus of composites prepared using Fiberlean dried with new approach. ................. 5 


\section{ACKNOWLEDGEMENTS}

This CRADA NFE- 15-05686 was conducted as a Technical Collaboration project within the Oak Ridge National Laboratory (ORNL) Manufacturing Demonstration Facility (MDF) sponsored by the US Department of Energy Advanced Manufacturing Office (CPS Agreement Number 24761).

Opportunities for MDF technical collaborations are listed in the announcement "Manufacturing Demonstration Facility Technology Collaborations for US Manufacturers in Advanced Manufacturing and Materials Technologies" posted at http://web.ornl.gov/sci/manufacturing/docs/FBO-ORNL-MDF2013-2.pdf. The goal of technical collaborations is to engage industry partners to participate in shortterm, collaborative projects within the Manufacturing Demonstration Facility (MDF) to assess applicability and of new energy efficient manufacturing technologies. Research sponsored by the U.S. Department of Energy, Office of Energy Efficiency and Renewable Energy, Advanced Manufacturing Office, under contract DE-AC05-00OR22725 with UT-Battelle, LLC.

We would like to thank Forest Products Laboratory for their help in freeze-drying some of the mineral-ground microfibrillated cellulose samples. 


\begin{abstract}
ORNL worked with Imerys to demonstrate reinforcement of additive manufacturing feedstock materials using mineral-ground microfibrillated cellulose (MFC). Properly prepared/dried mineralground cellulose microfibrils significantly improved mechanical properties of both ABS and PLA resins. While tensile strength increases up to $\sim 40 \%$ were observed, elastic modulus of the both resins doubled with the addition of $30 \%$ MFC.
\end{abstract}

\title{
1. MINERAL-GROUND MICRO-FIBRILLATED CELLULOSE REINFORCEMENT FOR POL YMER COMPOUNDS
}

This phase I technical collaboration project (MDF-TC-2015-067) was begun on December 14, 2015 and was completed on Dec 04, 2016. The collaboration partner Imerys is a large business. By use of properly processed/dried microfibrillated cellulose (MFC)-mineral composites (fiberlean), up to $40 \%$ increase in tensile strength and up to two-fold increase in elastic modulus were achieved compared to neat AM resins such as ABS and PLA.

\subsection{BACKGROUND}

Imerys is an industrial minerals company and a leading supplier of pigments for paper and packaging. Typical minerals produced by Imerys include kaolin, talc, mica, marble, graphite, perlite, and diatomaceous earth. Imerys also utilizes minerals to fibrillate cellulose to produce composites of minerals and Micro Fibrillated Cellulose (MFC). MFCs produced by the company are mainly used for the production of paper, and due to decreasing demand for paper because of digital communications; new areas for use of the cellulosic materials of the company are needed.

Use of fibrillar materials to improve the mechanical properties of polymer resins is an effective approach. Many studies on the use of carbon and glass fibers to improve to mechanical properties of common polymer resins were reported [1-6]. Use of bio-based cellulosic fibers ranging from cellulose nanocrystals to microfibrillated cellulose were also reported to improve the mechanical properties of both thermoset and thermoplastic polymers [7]. Therefore, potential use of Imerys' fiberlean to reinforce commonly used polymeric materials can open up new window of opportunities for Imerys. For this specific project, polymer resins suitable for additive manufacturing (AM) were chosen in order to demonstrate the application of the developed composite systems to large scale AM. Addition of mineral-MFC systems into the polymer resins are not only expected to improve the mechanical properties of the resin, but also expected to change the rheological properties, thus, printability of the material system.

For the successful incorporation of the MFCs products of Imerys into polymer systems and demonstration of the potential of the material as a reinforcing phase, proper drying/processing of the material systems were required. The Oak Ridge National Laboratory (ORNL) team has helped in that respect with their expertise in material and composite development and processing. A minimum increase in tensile strength (25\%) and elastic modulus (50\%) were set as the metrics for the success of the project.

\subsection{TECHNICAL RESULTS}

While the ultimate goal of this effort is to develop composite systems that are reinforced with 
mineral-ground MFCs, the specific goal of this project is to develop these systems using common AM polymers to eventually apply to AM. Because of this reason, acrylonitrile-butadiene-stryrene (ABS) and Polylactic acid (PLA) were chosen as matrix systems. Because the final mineral-MFC mixture produced by Imerys is wet, the product has to be dried prior to incorporation into polymer matrix. Because of the rich hydroxyl groups on the surface of the fibrils, fibrils may agglomerate due to strong hydrogen bonding during drying process, making dispersion of them difficult inside the polymer matrix. Therefore, proper drying and processing of fibrils and the polymers are required in order to achieve good dispersion, thus, good mechanical properties.

\subsubsection{Freeze-dried mineral-ground MFCs}

A calcium carbonate-ground MFC system (50\% mineral by wt) was chosen for initial testing and samples were dried by freeze drying approach by Forest Products Laboratory (FPL). This drying approach was chosen first as it yields low density final product which is easier to disperse in polymer matrix. The dried MFCs were compounded with polymer resins ABS and PLA at different compositions (10-30\%) using a high-shear mixer. Next, compounded materials were extruded into slitpreforms. Afterwards, the slit-preforms were cut at predetermined weights and compression molded into testing bars. The pressed bars were then cut into ASTM D638 type V tensile testing dog bones using a router and a template.

The tensile testing specimens were tested following ASTM D638. Tensile strength of both ABS and PLA resins increased with the increasing amount of MFCs and reached about $40 \%$ increase at 30\% (wt) fiberlean (mineral-ground MFC with mineral content in it) content for both resins (see

Fig. 1). A similar trend for the elastic modulus of the composite systems was also observed. The elastic modulus of both resins increased about $100 \%$ at $30 \%$ fiberlean content (see Fig. 2). Although for these initial tests only up to $30 \%$ fiberlean loadings were investigated, based on the continuous trend in both tensile strength and elastic modulus, one can expect further increase at higher loadings.

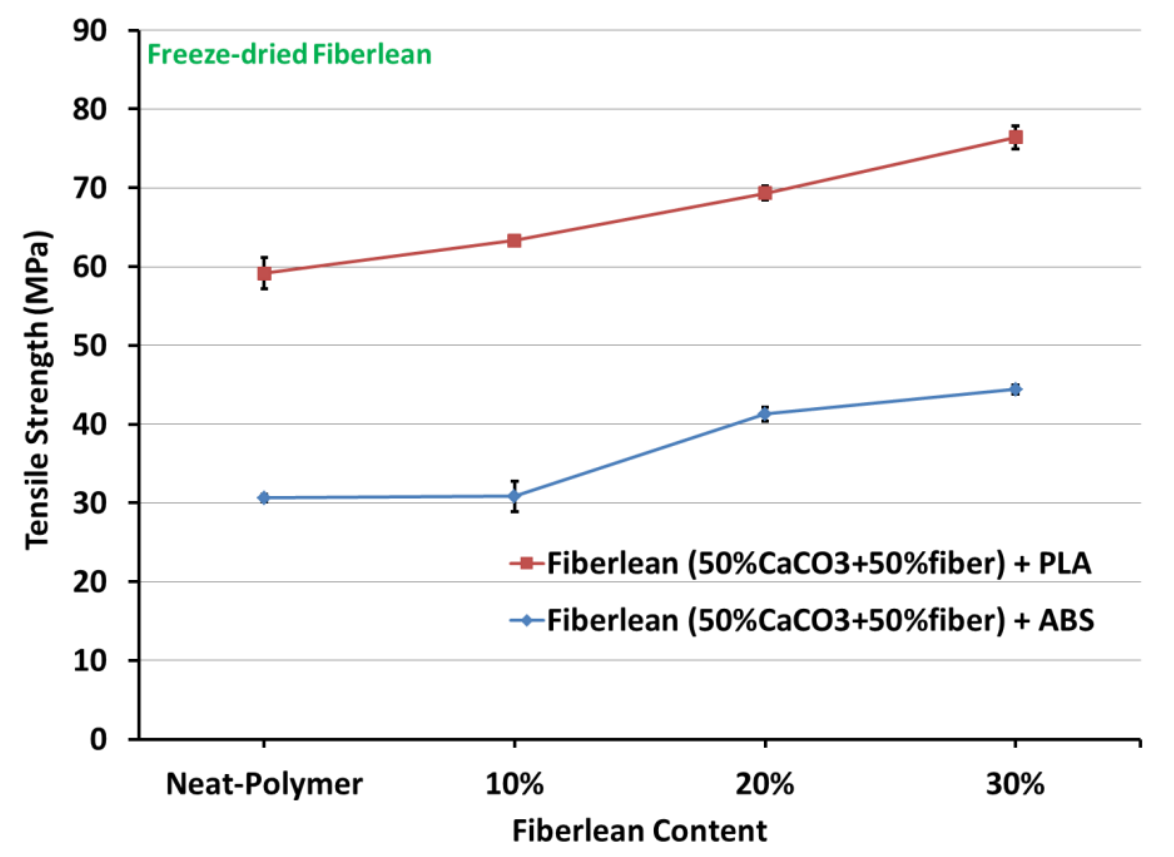

Fig. 1. Tensile strength of composites prepared using freeze-dried Fiberlean. 


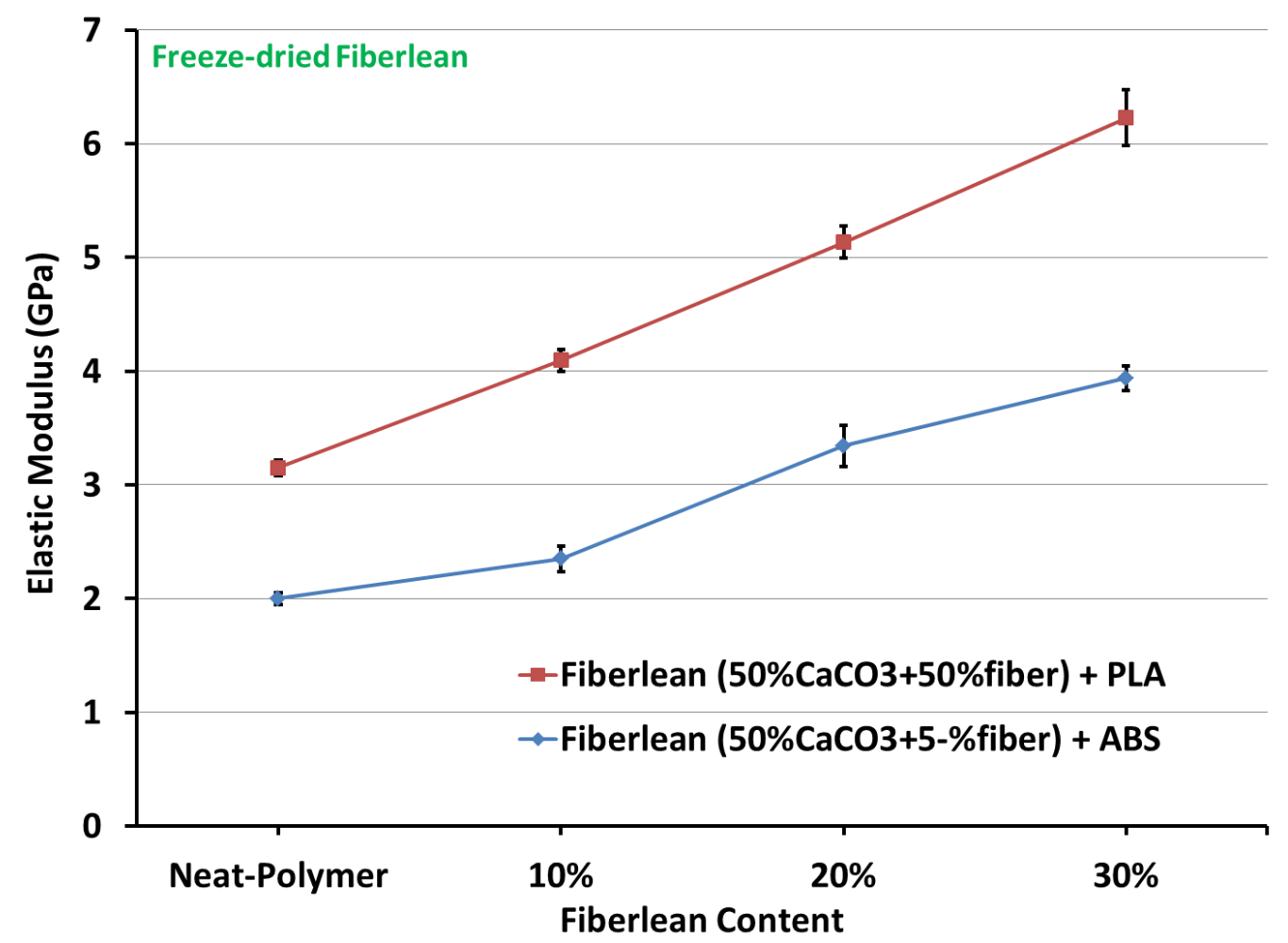

Fig. 2. Elastic modulus of composites prepared using freeze-dried Fiberlean.

After demonstration of improvements in tensile properties of the AM polymer resins, desktop scale 3D printer filaments with $10 \%$ fiberlean content were prepared using PLA as a base resin and printability of the reinforced composite material was demonstrated at small scale (see Fig. 3).

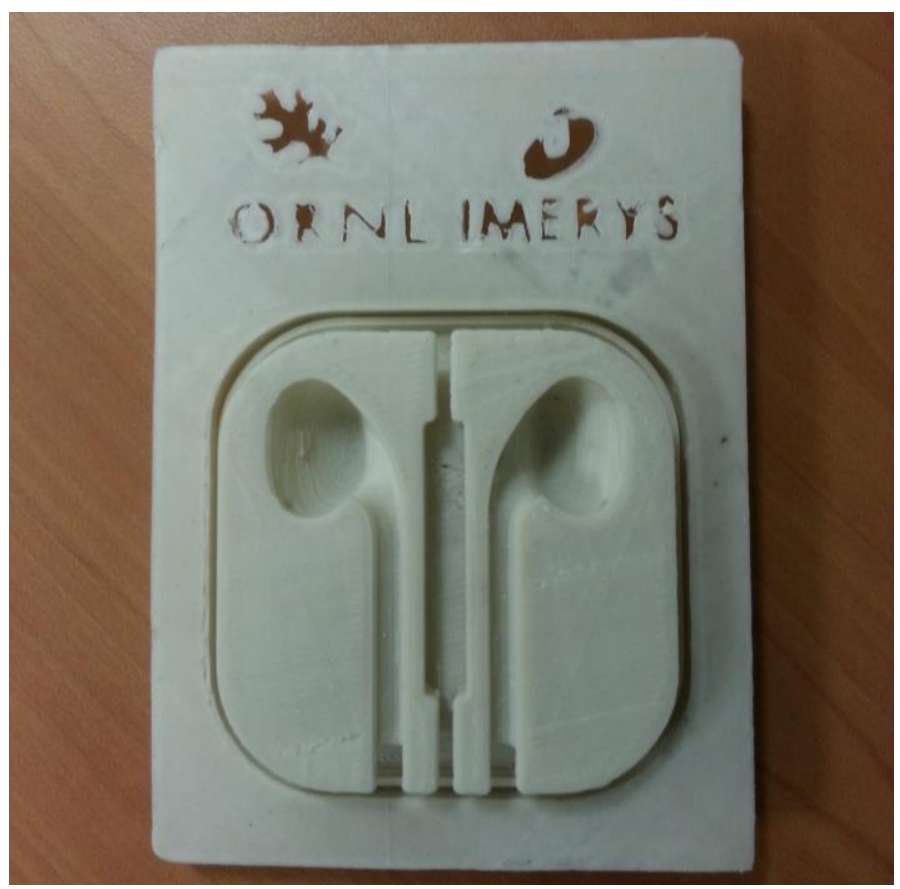

Fig. 3. Earbud case that was 3D-printed using $10 \%$ freeze-dried fiberlean and PLA. 


\subsubsection{New drying approach}

Although significant improvement in both tensile strength and elastic modulus were achieved using freeze-dried mineral-MFC systems, due to cost and scalability limitations, an alternative, industrially viable drying approach has been investigated. With this approach, mineral-MFC systems are planned to be incorporated into polymer resins in large quantities and at low cost. Since this approach is being developed by Imerys, details are not shared in this report. Initial trials with the new drying approach were conducted with three different mineral compositions using PLA resin. In addition to the same 50\% CaCO3-MFC composition as the freeze-dried fiberlean, 50\% talc-MFC composition and a composition with more than $90 \%$ MFC were investigated. Up to $40 \%$ fiberlean loadings were tested. The increase in tensile strength that was observed with the use of freeze-dried fiberlean was not observed with the new approach (see Fig. 4). However, significant increase in elastic modulus of the composite systems compared to the neat PLA was observed (see Fig. 5). This suggests the need for further improvement in drying and compounding of cellulose microfibrils at large scale. The work on the development of new, scalable drying approach is continuing and we expect improved results soon. Once the strength is also improved, scalable high volume drying approach will be a great step towards commercialization.

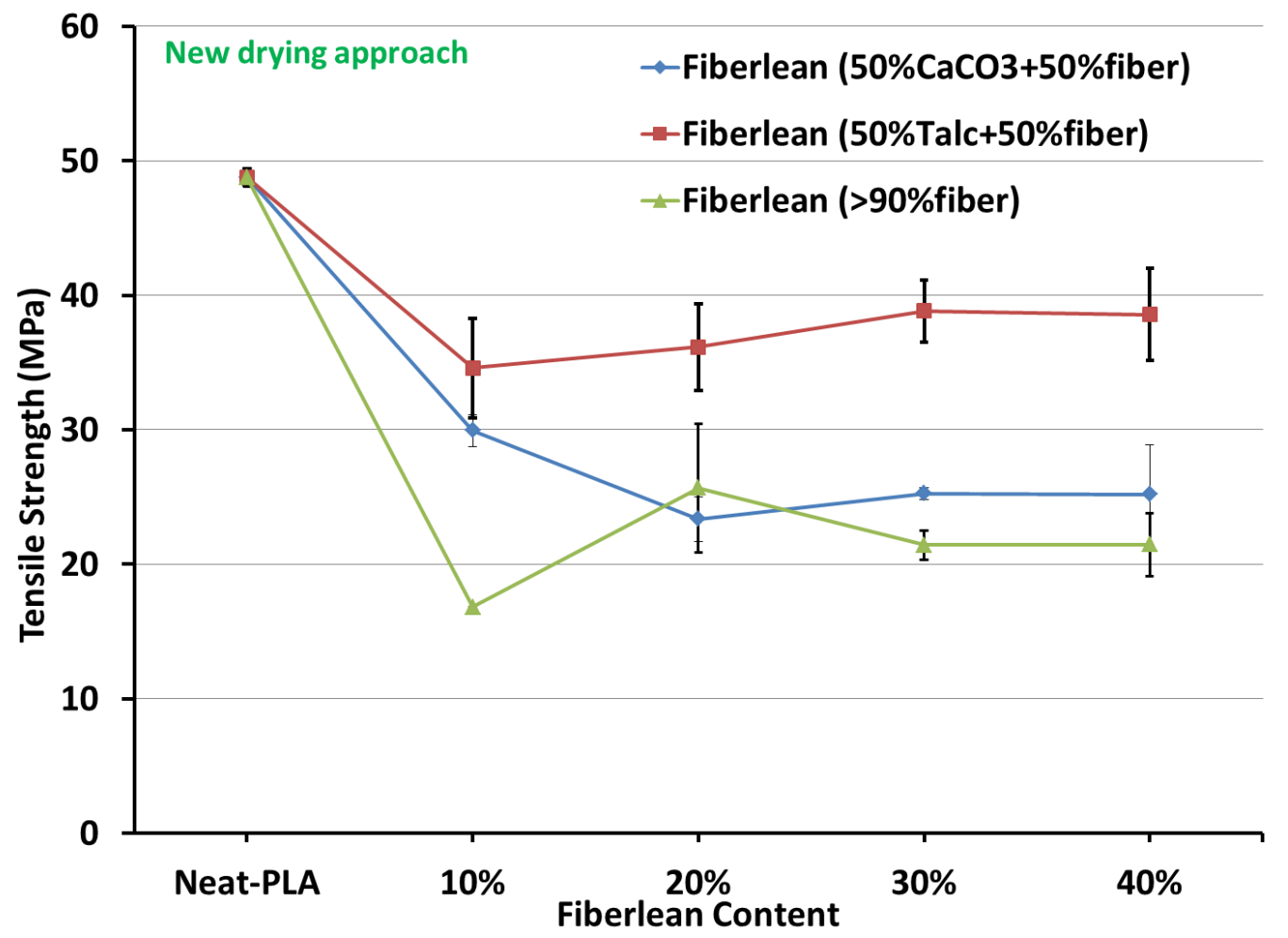

Fig. 4. Tensile strength of composites prepared using Fiberlean dried with new approach. 


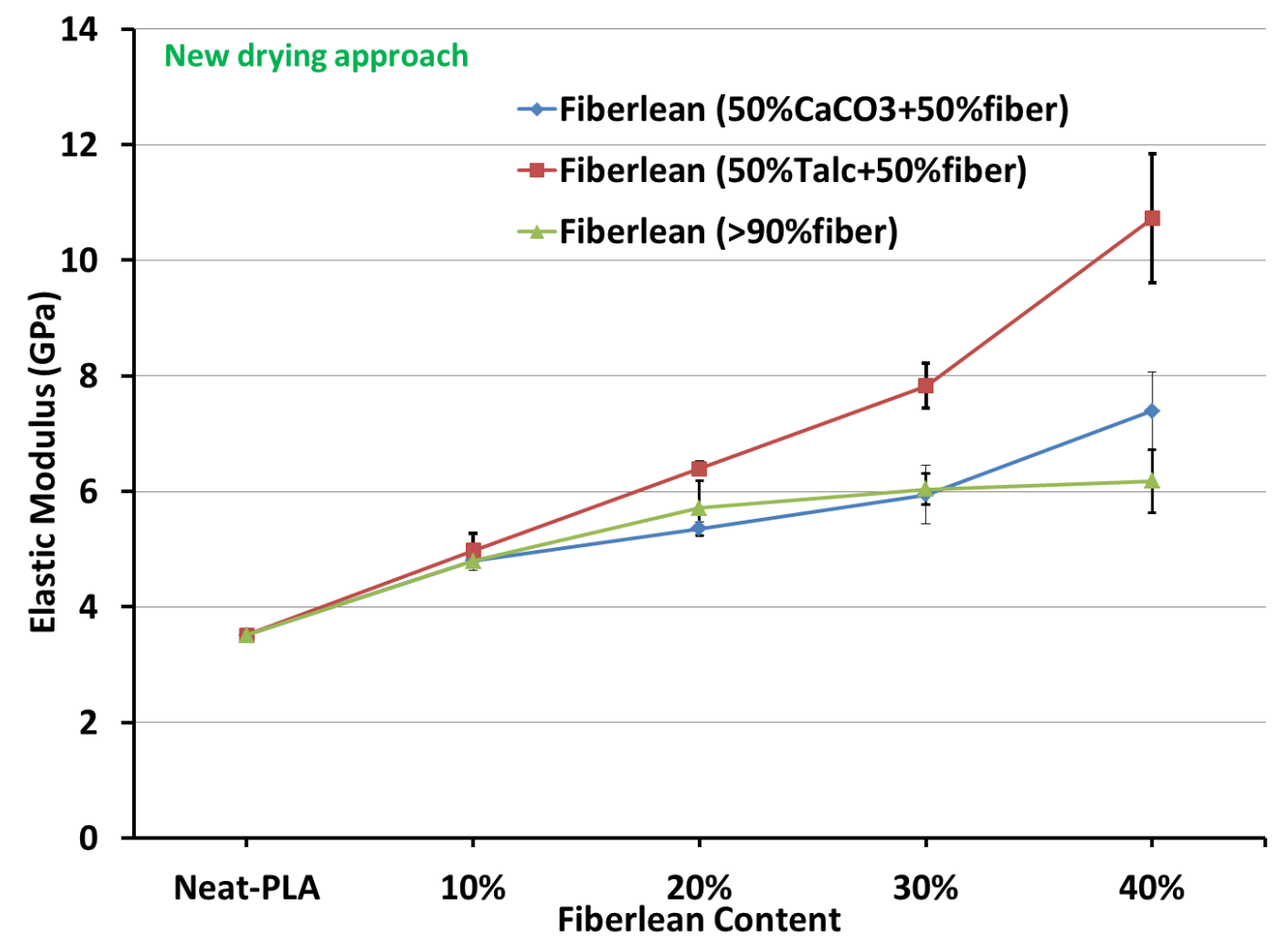

Fig. 5. Elastic modulus of composites prepared using Fiberlean dried with new approach.

\subsection{IMPACTS}

Additive Manufacturing (AM) is quickly becoming a mainstream, energy efficient manufacturing technique for complex and custom components. ORNL has taken polymer AM into the next level with Big Area Additive Manufacturing (BAAM). However, we need to develop the strength of AM materials (specifically polymers) to satisfy the mechanical requirements of structural parts. Also, it is crucial that the developed process can easily be scaled up to have a significant impact in the manufacturing industry of US. Furthermore, renewable, bio-derived AM materials are desirable from a sustainability perspective.

This project showed the potential of low cost mineral-ground micro-fibrillated cellulose systems that are derived from biomass to improve the mechanical properties of polymer AM components by creating composite material systems. Imerys' new technology employs minerals as fine grinding agents, resulting in low cost MFC with mineral additives. This process not only can provide low cost MFCs for large scale composite applications such as BAAM, but also can stimulate new products and revenue sources for the US forest products and mineral industries. Micro-fibrillated cellulose is a wood-based renewable resource; and from the perspective of national competitiveness and security, micro/nano-cellulose and bio-resins are likely to be domestically sourced, creating US jobs especially in rural areas. Furthermore, feedstock from renewable and biocompatible resources will minimize America's dependency on petroleum products.

To illustrate, Imerys is in the commissioning phase of a new FiberLean facility on a large paper mill site in the eastern US. Six full-time staff members with competitive wages, benefits, and health insurance will be hired to operate the plant. Also, during the year of design and construction, seven full time engineers and 38 full time construction workers will be employed. Furthermore, the local economy will benefit additional revenues in the areas of industrial equipment purchases, bulk transportation (trucks, tankers), local food and hospitality, car rental, airport and continued 
maintenance of the plant.

\subsection{CONCLUSIONS}

The results of the project showed that the fiberlean product (mineral-ground microfibrillated cellulose) has the potential to improve the mechanical properties of common AM polymer resins, ABS and PLA, significantly provided that the right drying and processing approaches are employed. Using freeze-dried fiberlean product, the tensile strengths of neat AM polymers were increased about $40 \%$, while their elastic modulus increased about $100 \%$. Therefore, the project metrics were successfully met. Printability of one of the compositions was demonstrated at desktop scale.

After demonstration of the reinforcing potential of the partner's product, now there is a search for developing a scalable, faster drying and compounding process that can yield fibrils with similar low density morphology to those dried via freeze-drying process. Once the large scale drying process is completed, formulation will be optimized for both the mechanical properties and the suitability for AM in large scale.

\subsection{REFERENCES}

1. Tekinalp HL, Kunc V, Velez-Garcia GM, Duty CE, Love LJ, Naskar AK, Blue CA, Ozcan S. Highly oriented carbon fiber-polymer composites via additive manufacturing. Compos Sci Technol 2014;105:144-50.

2. Karsli NG, Aytac A. Tensile and thermomechanical properties of short carbon fiber reinforced polyamide 6 composites. Composites Part B 2013;61:270-5

3. Botelho EC, Figiel L, Rezende MC, Lauke B. Mechanical behavior of carbon fiber reinforced polyamide composites. Compos Sci Technol 2003;63:1843-55.

4. Tezcan J, Ozcan S, Gurung B, Filip P. Measurement and analytical validation of interfacial bond strength of PAN-fiber-reinforced carbon matrix composites. J Mater Sci 2008;43(5):1612-8.

5. Fu SY, Lauke B, Mader E, Yue CY, Hu X. Tensile properties of short-glass-fiber and short-carbon-fiber-reinforced polypropylene composites. Composites Part A 2000;31:1117-25

6. Zhong W, Li F, Zhang Z, Song L, Li Z. Short fiber reinforced composites for fused deposition modeling. Mater Sci Eng A 2001;301:125-30

7. Lu Y, Tekinalp HL, Eberle CC, Peter W, Naskar AK, Ozcan S. Nanocellulose in polymer composites and biomedical applications. TAPPI J 2014; 13(6):47-54 


\section{PARTNER BACKGROUND}

Imerys is an Industrial Minerals company and a leading supplier of pigments for paper and packaging. Typical minerals produced by Imerys include kaolin, talc, mica, marble, graphite, perlite, and diatomaceous earth. Imerys also produces composites of minerals and Micro Fibrillated Cellulose (nanocellulose). 